\title{
О ХИМИЧЕСКОМ СОСТАВЕ САПРОПЕЛЕЙ ОМСКОЙ ОБЛАСТИ
}

\author{
() О.И. Кривонос ${ }^{l *}$, Г.В. Плаксин ${ }^{1,2}$, В.Н. Носенко ${ }^{2}$ \\ ${ }^{1}$ Институт проблем переработки углеводородов СО РАH, \\ ул. Нефртезаводская, 54, Омск, 644040 (Россия), e-mail: oksana@ihcp.ru \\ ${ }^{2}$ Омский государственный университет им. Ф.М. Достоевского, ул. Мира, \\ 55а, Омск, 644077 (Россия)
}

Исследованы химический состав и физико-химические свойства сапропелей различных месторождений Омской области. Установлены закономерности, связывающие состав и свойства сапропелей, а также влияние температурной обработки на выход продуктов.

Ключевые слова: сапропель, химический состав, биогенные микроэлементы, аминокислоты, полукоксование сапропелей.

\section{Введение}

Сапропели характеризуются сложным химическим составом как органической, так и минеральной составляющей, соотношение которых меняется в широком диапазоне. Органическая составляющая сапропелей представляет собой совокупность растительных и животных остатков и продуктов их распада. В ее составе присутствуют соединения кислотной природы, гуминовые вещества, обладающие различными функциональными группами, а в составе минеральной - оксиды железа, алюминия, силикаты, минералы простых кислородсодержащих солей, основная долю составляют карбонаты [1-6]. До недавнего времени основные исследования были направлены на изучение химического состава, биологических и агрохимических свойств озерных сапропелей Западной и Европейской части России, Белоруссии, Латвии, хотя Западная Сибирь является одним из ведущих регионов сапропелеобразования. Только в Омской области запасы сапропелей составляют около 300 млн. м³ [7]. Для рационального использования и определения подходов к переработке данного сырья необходимы знания о химическом составе минеральной и органической составляющей. Ранее проведенные оценочные исследования для трех сапропелей различных месторождений Омской области показали, что в образцах отсутствуют радиоактивные загрязнения, а содержание тяжелых металлов гораздо ниже предельно допустимых концентраций, содержание органического вещества (ОВ) варьируется в диапазоне 71-83\% масс, а высокое содержание азота - более $10 \%$ масс. на ОВ свидетельствует о перспективности их дальнейшей переработки [8-10].

В настоящей работе приводятся результаты исследования химического состава и физико-химических

Кривонос Оксана Ивановна - научный сотрудник лаборатории каталитических превращений углеводородов, кандидат химических наук, e-mail: koi1981@mail.ru

Плаксин Георгий Валентинович - главный научный сотрудник лаборатории каталитических превращений углеводородов, профессор кафедры химической технологии, доктор химических наук, e-mail: plaksin@ihcp.ru

Носенко Валентина Николаевна - доцент кафедры химической технологии, кандидат химических наук, e-mail: nosenko@chemomsu.ru свойств сапропелей различных месторождений Омской области с привлечением современной инструментальной базы, установлен ряд закономерностей, связывающих состав и свойства сапропелей.

\section{Экспериментальная часть}

В качестве исследования были выбраны озера 21-го месторождения Омской области, перспективные для промышленного освоения. Образцы сапропелей отбирались из придонных областей централь-

\footnotetext{
* Автор, с которым следует вести переписку.
} 
ной части озера. Бурение проводилось на 4-5 пунктах. Образцы объединялись, усреднялись и далее подвергались исследованию. Такой подход позволяет охарактеризовать средние свойства сапропелей.

Содержание влаги $\left(\mathrm{W}^{\mathrm{a}}\right)$ в аналитической пробе определялось - по ГОСТ 27314-91 «Топливо твердое минеральное. Методы определения влаги»; насыпная плотность ( $\rho$, г/см $\left.{ }^{3}\right)$ по ГОСТ 16190-70 «Сорбенты. Метод определения насыпной плотности» и зольность $\left(\mathrm{A}^{\mathrm{c}}\right)$ - по ГОСТ 11022-95 «Топливо твердое минеральное. Методы определения зольности».

Элементный состав OB определялся на CHNOS-элементном анализаторе Vario EL Cube фирмы «Elementar nalysensysteme GmbH» (Германия). Термический анализ проводился на приборе DTG-60H «Shimadzu» в интервале температур $30-1000^{\circ} \mathrm{C}$ в атмосфере аргона. Качественный и количественный состав минеральной части изучался методами рентгено-флуоресцентной спектрометрии на приборе OPTIM'X фирмы «ARL» с пределом обнаружения 0,0001-0,01\% масс. и атомно-абсорбционной спектрофотометрии на приборе AAS 6300 фирмы «Shimadzu».

Микрорельеф поверхности сапропелей изучали методом сканирующей электронной микроскопии (SEM) с энергодисперсионной спектрометрией (EDS) на микроскопе марки JSM-6610 LV «JEOL».

Выход продуктов полукоксования определялся по ГОСТ 3168-93 «Топливо твердое минеральное. Метод ускоренного определения выхода продуктов полукоксования».

Анализ аминокислот осуществлялся на колонке LiChrospher 100 RP-18 250-4 (125×4 мм, размер частиц носителя 5 мк), температура колонки $40{ }^{\circ} \mathrm{C}$, подвижная фаза метанол: раствор ацетата натрия $0,05 \mathrm{M}, \mathrm{pH}=7$, скорость потока 1 мл/мин, детектирование проводилось на флуоресцентном детекторе при 330 и 450 нм.

\section{Результаты и обсуждение}

Характеристики исследованных сапропелей представлены в таблице 1.

Реакция среды сапропелей исследованных озер Омской области в основном щелочная и близкая к нейтральной. Подкисленные сапропели (рН 5,38) встречаются в единичных случаях, в Омской области это сапропель месторождения озера Пучай.

Сапропелевое сырье всех без исключения исследованных озер является экологически чистым по составу - суммарный показатель загрязнения, рассчитанный для 12 токсикантов, значительно меньше 1.

Содержание ОВ в сапропелях варьируется в широких пределах: от 8,5 до 83\% на сухое вещество (СВ).

Таблица 1. Характеристики сапропелей Омской области

\begin{tabular}{|c|c|c|c|c|c|c|}
\hline \multirow[b]{2}{*}{ Месторождение } & \multirow{2}{*}{$\begin{array}{c}\text { Показатель за- } \\
\text { грязнения }\end{array}$} & \multicolumn{5}{|c|}{ Физико-химические показатели } \\
\hline & & $\mathrm{pH}$ & $\rho, \Gamma / \mathrm{cm}^{3}$ & $\begin{array}{l}W_{h}, \\
\% \text { вec }\end{array}$ & $\begin{array}{c}\text { Содержание OB, \% } \\
\text { масс }\end{array}$ & $A^{d}, \%$ масс \\
\hline Тобол-Кушлы & $-8,82$ & 8,52 & 0,76 & 69 & 8,5 & 91,5 \\
\hline Кривое & $-9,61$ & 7,48 & 0,81 & 84 & 13,0 & 87,0 \\
\hline Чебак & $-9,01$ & 7,54 & 0,79 & 75 & 13,3 & 86,7 \\
\hline Чистое & $-9,18$ & 8,10 & 0,78 & 43 & 13,7 & 86,3 \\
\hline Соленое & $-7,89$ & 8,70 & 0,53 & 77 & 23,2 & 76,8 \\
\hline Калмакульское & $-8,12$ & 8,30 & 0,51 & 82 & 35,7 & 64,3 \\
\hline Горькое & $-7,41$ & 8,60 & 0,48 & 77 & 36,0 & 64,0 \\
\hline Интенис & $-5,29$ & 8,17 & 0,46 & 70 & 52,8 & 47,2 \\
\hline Пучай & $-8,40$ & 5,38 & 0,45 & 65 & 54,3 & 45,7 \\
\hline Темное & $-4,68$ & 8,28 & 0,39 & 85 & 58,1 & 43,0 \\
\hline Атаманское & $-9,39$ & 7,20 & 0,37 & 74 & 67,0 & 33,0 \\
\hline Пахарево & $-9,22$ & 6,95 & 0,33 & 87 & 70,0 & 30,0 \\
\hline Жилой Рям & $-8,94$ & 5,64 & 0,32 & 63 & 71,0 & 29,0 \\
\hline Кайлы & $-8,14$ & 7,83 & 0,30 & 72 & 73,0 & 27,0 \\
\hline Молодавское & $-8,47$ & 7,08 & 0,28 & 68 & 73,2 & 26,8 \\
\hline Горчаково & $-7,99$ & 7,55 & 0,34 & 85 & 73,9 & 26,1 \\
\hline Ачикуль & $-8,50$ & 8,15 & 0,32 & 87 & 74,0 & 26,0 \\
\hline Большой Артеев & $-9,22$ & 7,50 & 0,28 & 81 & 76,7 & 23,3 \\
\hline Мезенино & $-8,56$ & 6,91 & 0,29 & 70 & 77,0 & 23,0 \\
\hline Молоковское & $-8,31$ & 7,12 & 0,37 & 75 & 79,0 & 21,0 \\
\hline Лепешкин Рям & $-9,40$ & 5,29 & 0,31 & 84 & 83,0 & 17,0 \\
\hline
\end{tabular}


Элементный состав сапропелей Омской области (табл. 2) колеблется в следующих пределах: 41,82-53,85\% углерода на ОВ, 5,49-7,60\% водорода, 0,75-2,45\% серы и 36,87-50,42\% приходится на азот и кислород, при этом в некоторых образцах содержание азота достигает 9,88\%. Различия содержания углерода, водорода и азота обусловлены соотношением видов сапропелеобразователей, формировавших OB. Невысокий уровень углерода и повышенный азота и кислорода характерен для сапропелей эвтрофных водоемов, накапливающих $\mathrm{OB}$ за счет планктонного генезиса.

Причем высокое содержание азота и кислорода, >5 и >30\%, соответственно, в большинстве исследуемых образцах сапропелей свидетельствует о низкой сте-
Таблица 2. Элементный состав сапропелей Омской области

\begin{tabular}{l|c|c|c|c|c}
\hline \multirow{2}{*}{ Месторождение } & \multicolumn{5}{|c}{ Состав, \% на daf } \\
\cline { 2 - 6 } & $\mathrm{C}$ & $\mathrm{H}$ & $\mathrm{S}$ & $\mathrm{N}$ & $\mathrm{O}$ \\
\hline Калмакульское & 49,15 & 7,60 & 1,47 & 4,76 & 37,02 \\
Горькое & 43,52 & 6,55 & 1,17 & \multicolumn{2}{|c}{48,76} \\
Интенис & 45,67 & 5,99 & 1,24 & 3,86 & 43,24 \\
Пучай & 41,82 & 6,82 & 0,94 & 7,37 & 43,05 \\
Темное & 45,17 & 5,49 & 1,32 & \multicolumn{2}{|c}{48,02} \\
Атаманское & 52,31 & 6,90 & 1,09 & 3,91 & 35,79 \\
Пахарево & 52,72 & 6,91 & 1,12 & 4,37 & 34,88 \\
Жилой Рям & 52,12 & 7,39 & 0,82 & 9,88 & 29,79 \\
Кайлы & 51,35 & 6,52 & 1,71 & 3,64 & 36,78 \\
Молодавское & 53,09 & 6,23 & 0,69 & 8,43 & 31,56 \\
Горчаково & 49,80 & 6,45 & 1,18 & 5,27 & 37,30 \\
Большой Артев & 51,03 & 7,95 & 0,91 & \multicolumn{2}{|c|}{40,11} \\
Мезенино & 45,74 & 6,51 & 0,76 & 9,63 & 37,36 \\
Молоковское & 53,85 & 6,83 & 2,45 & \multicolumn{3}{|c}{36,87} \\
Лепешкин Рям & 53,70 & 6,98 & 0,75 & 8,12 & 30,45 \\
\hline
\end{tabular}
пени разложения ОВ, что подразумевает перспективность их глубокой переработки.

Подробно изучен химический состав минеральной части сапропелей Омской области (табл. 3). Все изученные сапропели Омской области, за исключением одного отложения месторождения оз. Чистое, по классификации Е.М. Титова относятся к типу кремнеземистых $\left(\mathrm{SiO}_{2}>50 \%\right)$. Повышенным содержанием кальция $(\mathrm{CaO}>10 \%)$ характеризуются отложения озер Интенис и Темное. Для некоторых сапропелей характерно повышенное содержание $\mathrm{SO}_{3}$ (более 4\%), озера Пучай, Молодавское, Горчаково, Ачикуль и Лепешкин Рям, что указывает на присутствие сульфата.

Количество $\mathrm{P}_{2} \mathrm{O}_{5}$ в минеральной части колеблется в пределах 0,04-0,68\%, причем большим содержанием фосфора характеризуются сапропели малозольные и среднезольные (Пучай, Жилой Рям, Молодавское, Горчаково, Ачикуль и Лепешкин Рям).

Содержание $\mathrm{Fe}_{2} \mathrm{O}_{3}$ в зольной части сапропелей колеблется в диапазоне 0,76-3,30\%; наиболее богаты этим компонентом сапропели преимущественно повышенной зольности (озера Чебак, Соленое, Калмакульское, Горькое).

Таблица 3. Химический состав минеральной части сапропелей Омской области

\begin{tabular}{|c|c|c|c|c|c|c|}
\hline \multirow{2}{*}{ Месторождение } & \multicolumn{6}{|c|}{ Содержание, \% на сухое вещество } \\
\hline & $\mathrm{P}_{2} \mathrm{O}_{5}$ & $\mathrm{~K}_{2} \mathrm{O}$ & $\mathrm{CaO}$ & $\mathrm{Fe}_{2} \mathrm{O}_{3}$ & $\mathrm{SO}_{3}$ & $\mathrm{SiO}_{2}$ \\
\hline Тобол-Кушлы & 0,04 & 0,69 & 2,19 & 2,16 & 0,97 & 51,3 \\
\hline Кривое & 0,14 & 0,78 & 1,75 & 2,00 & 0,93 & 59,8 \\
\hline Чебак & 0,18 & 0,85 & 3,40 & 3,30 & 0,75 & 62,2 \\
\hline Чистое & 0,14 & 0,45 & 1,57 & 1,46 & 0,23 & 48,9 \\
\hline Соленое & 0,18 & 0,89 & 4,71 & 3,06 & 2,24 & 61,4 \\
\hline Калмакульское & 0,12 & 0,93 & 2,75 & 2,67 & 1,99 & 66,8 \\
\hline Горькое & 0,10 & 0,63 & 4,17 & 2,35 & 2,11 & 63,4 \\
\hline Интенис & 0,14 & 0,55 & 12,00 & 1,83 & 2,81 & 64,2 \\
\hline Пучай & 0,50 & 0,20 & 2,86 & 1,18 & 4,42 & 65,1 \\
\hline Темное & 0,18 & 0,26 & 15,00 & 1,04 & 3,08 & 62,9 \\
\hline Атаманское & 0,25 & 0,39 & 1,46 & 1,40 & 1,96 & 60,3 \\
\hline Пахарево & 0,26 & 0,37 & 2,63 & 1,70 & 1,05 & 55,9 \\
\hline Жилой Рям & 0,50 & 0,16 & 1,43 & 1,34 & 2,97 & 67,3 \\
\hline Молодавское & 0,68 & 0,21 & 2,60 & 1,25 & 5,87 & 50,9 \\
\hline Горчаково & 0,40 & 0,36 & 2,40 & 1,92 & 4,74 & 48,8 \\
\hline Ачикуль & 0,37 & 0,18 & 4,78 & 0,76 & 5,67 & 49,1 \\
\hline Лепешкин Рям & 0,57 & 0,40 & 1,82 & 0,99 & 4,52 & 55,1 \\
\hline
\end{tabular}


Кроме указанных макроэлементов в составе минеральной части обнаружены и жизненно важные микроэлементы, входящие в состав металлоферментов и металлопротеидов, обеспечивающих многие физиологические процессы в организмах животных и человека: марганец (117-873 мг/кг), хром (4,0339,8 мг/кг), никель (9,36-25,6 мг/кг), цинк (23,4- 75,4 мг/кг), кадмий $(0,20-0,82$ мг/кг), молибден (0,291,37 мг/кг), кобальт (3,52-13,1 мг/кг), медь (8,36-18,7 мг/кг) (табл. 5). В следовых количествах обнаружены олово, стронций, итрий, рубидий, титан, бром, хлор, цезий, бериллий, скандий, свинец, вольфрам.

Электронная микроскопия показала, что сапропели представляют собой бесструктурную массу, с отдельными фрагментами размером 1-10 $\mu \mathrm{m}$ (рис. 1).

Элементный анализ поверхности, выполненный методом EDS, показал наличие углерода (54,22-57,12\% масс), кислорода (33,08-36,16\% масс), серы (0,49-0,79\% масс), кремния $(1,75-3,89 \%$ масс), железа (1,32-5,05\% масс), натрия (0,16-0,18\% масс), магния $(0,13-0,14 \%$ масс), алюминия $(0,31-0,35 \%$ масс), калия $(0,18-0,81 \%$ масс), кальция $(0,83-2,14 \%$ масс), хлора $(0,14-0,22 \%$ масс), марганца $(0,25 \%$ масс), меди (0,63-1,09\% масс).

На рисунке 2 приведены кривые ДТА и ТГ, из которых видно, что для всех образцов сапропелей характерно три ступени распада: 50-220, 220-430 и 430-650 ${ }^{\circ} \mathrm{C}$. Стадии по величине потери массы отличаются друг от друга. В диапазоне температур 50-220 ㄷ происходит удаление адсорбционной воды и потеря массы составляет 8,7-10,9\%. Наибольшая потеря массы для всех образцов сапропелей наблюдается в интервалах температур $220-430{ }^{\circ} \mathrm{C}(35,6-42,6 \%)$ и $430-650{ }^{\circ} \mathrm{C}(24,2-35,9 \%)$, когда происходит деструкция органического вещества

На кривых ДТА в области 50-220 ㄷ наблюдается эндотермический эффект, который свидетельствует об удалении молекул воды. В диапазоне температур 220-430 ${ }^{\circ} \mathrm{C}$ кривые ДТА имеют раздвоенный экзотермический пик с максимумами 350 и $375^{\circ} \mathrm{C}$ и следующий экзотермический пик с максимумами при 496, 515 и $550{ }^{\circ} \mathrm{C}$, свидетельствуют о перестройке структурных фрагментов органического вещества сапропелей, разрыве углерод-углеродных связей. Для сапропелей оз. Лепешкин Рям и Горькое наблюдается эндотермический эффект с максимумами 532 и $564{ }^{\circ} \mathrm{C}$, который связан с удалением летучих соединенийпродуктов деструкции органического вещества. Причем для сапропеля озера Молодавское экзотермические эффекты в области $220-650{ }^{\circ} \mathrm{C}$ более выраженные. Свыше $650{ }^{\circ} \mathrm{C}$ наблюдается незначительная потеря массы (4,3-7,3\%), связанная с разложением минеральной части. Общие потери массы (на сухой сапропель) в процессе термического разложения составляют 79,7-96,7\%.
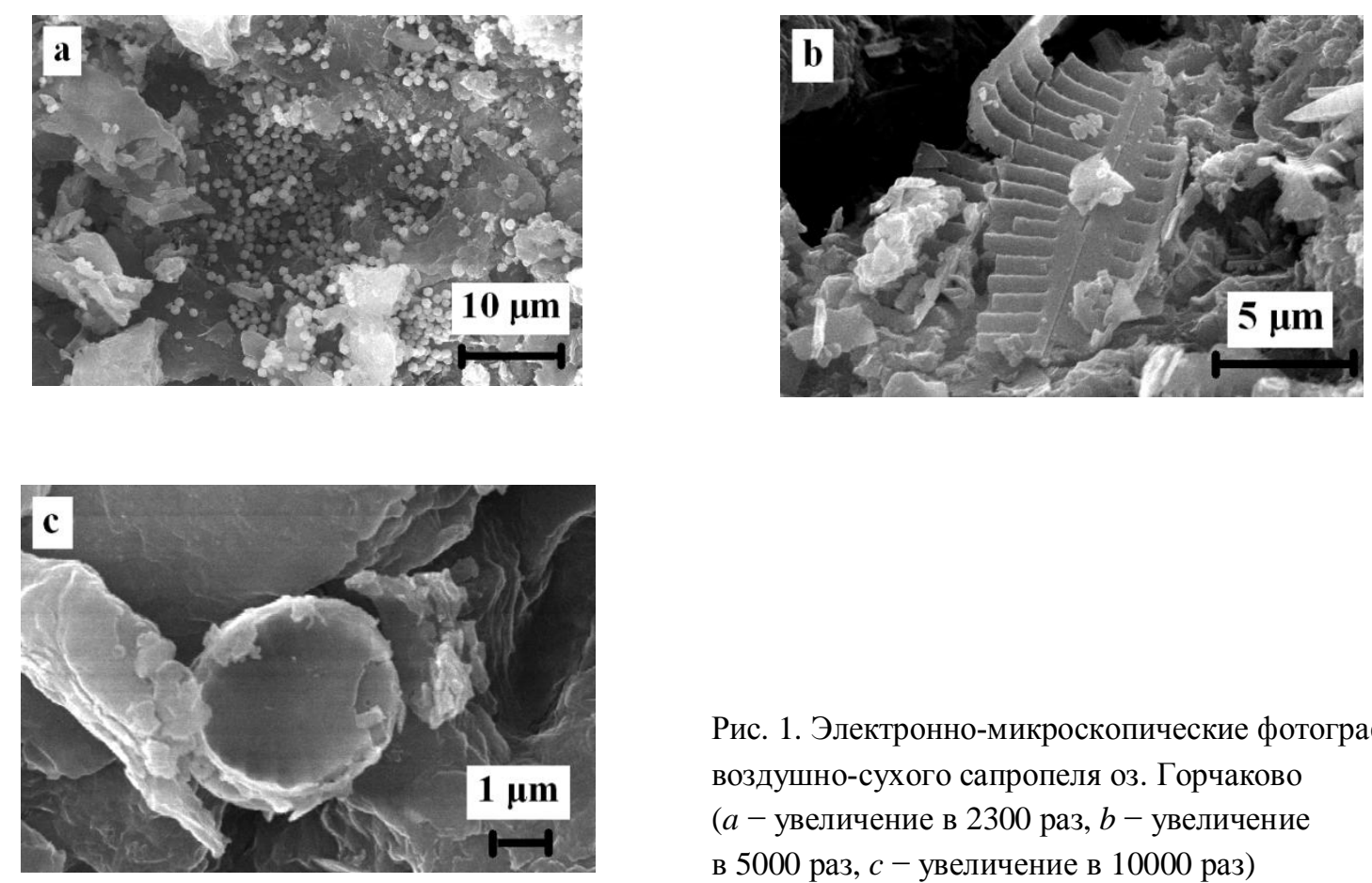

Рис. 1. Электронно-микроскопические фотографии воздушно-сухого сапропеля оз. Горчаково ( $a$ - увеличение в 2300 раз, $b$ - увеличение в 5000 раз, $c-$ увеличение в 10000 раз) 
Рис. 2. Кривые термического анализа сапропелей различных месторождений (1a (ТГ), $1 \mathrm{~b}$ (ДТА) - Молоковское, 2a (ТГ), 2b (ДТА)

- Горькое, 3а (ТГ), $3 \mathrm{~b}$ (ДТА) Лепешкин Рям)

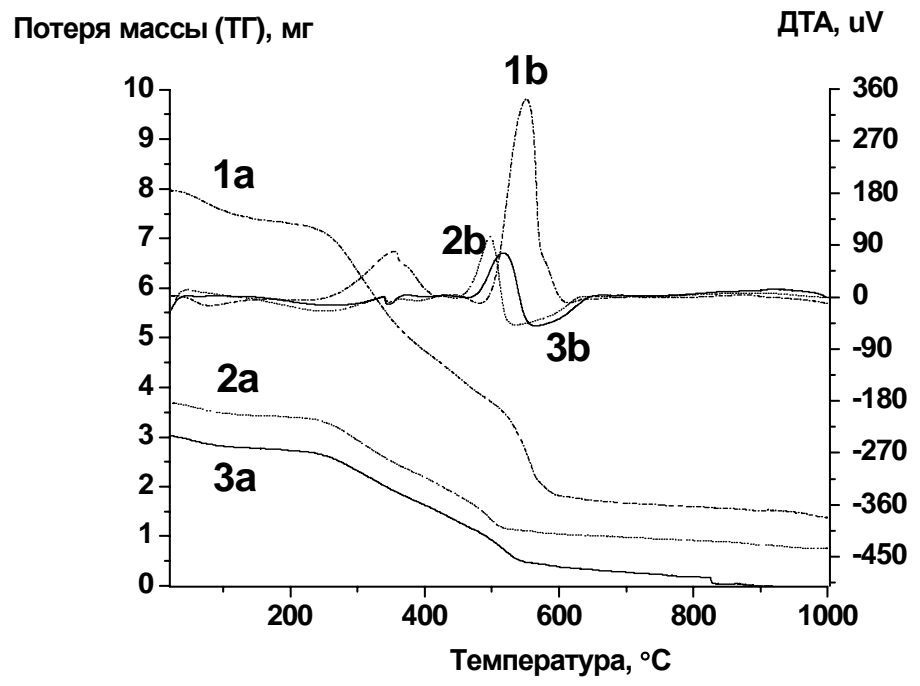

Компонентный состав ОВ сапропелей достаточно сложен и зависит от исходного материала и условий образования. Основными фракциями ОВ сапропелей Омской области являются гуминовые (40,1-47,0\% на ОВ) и легкогидролизуемые вещества $(23,9-31,2 \%$ на ОВ), которые составляют более половины ОВ. Содержание битумов в образцах колеблется в диапазоне 2,1-4,4\% на ОВ, на долю водорастворимых веществ приходится 3,6-5,3\% на ОВ.

В образцах сапропелей содержится мало трудногидролизуемых веществ (5,7-8,7\% на ОВ), что объясняется низким содержанием целлюлозных компонентов исходном материале и значительным преобразованием ОВ в процессе формирования сапропелей [12].

Невысокие значения содержания углеводного комплекса для всех образцов (включающего водорастворимые, легкогидролизуемые и трудногидролизуемые вещества) говорят о том, что значительная часть исходного растительного материала в результате реакции конденсации расходуется на образование гуминовых веществ.

Изучен аминокислотный состав нативных сапропелей Омской области (табл. 4).

Таблица 4. Содержание аминокислот в сапропелях Омской области (×10³ мг/кг Св)

\begin{tabular}{c|l|c|c|c}
\hline \multirow{2}{*}{ № } & \multirow{2}{*}{ Название аминокислоты } & \multicolumn{3}{|c}{ Месторождение } \\
\cline { 3 - 4 } & & Жилой Рям & Большой Артев & Пучай \\
\hline 1 & Аспарагиновая кислота & 0,41 & 1,08 & 0,95 \\
2 & Глутаминовая кислота & 0,31 & 0,88 & 0,42 \\
3 & Серин & 0,16 & 0,46 & 0,21 \\
4 & Гистидин & 0,35 & 0,21 & 0,75 \\
5 & Глицин & 0,38 & 0,77 & 0,51 \\
6 & Треонин & 0,18 & 0,49 & 0,48 \\
7 & Аргинин & 0,12 & 0,27 & 0,59 \\
8 & Аланин & 0,24 & 0,46 & 0,31 \\
9 & Тирозин & 0,14 & 0,27 & 0,56 \\
10 & Валин & 0,19 & 0,55 & 0,52 \\
11 & Фенилаланин & 0,14 & 0,40 & 0,35 \\
12 & Изолейцин & 0,15 & 0,33 & 0,53 \\
13 & Лейцин & 0,18 & 0,51 & 0,41 \\
14 & Лизин & 0,12 & 0,37 & 0,15 \\
15 & Цистин & 0,04 & 0,11 & 0,15 \\
16 & Метионин & 0,08 & 0,15 & не обнаружен \\
17 & Триптофан & 0,03 & 0,36 \\
18 & Пролин & не обнаружен & 8,27 \\
\hline
\end{tabular}


В нативных сапропелях исследуемых месторождений содержится по 17 аминокислот, сумма которых составляет 3,22-8,27 г/кг Св. Причем в сапропеле оз. Жилой Рям отсутствует пролин, однако обнаружен триптофан. Основную долю для всех сапропелей составляют глицин $(0,38-0,77$ г/кг Св), аспарагиновая $\left(0,41-1,08\right.$ г/кг $\left.\Gamma_{\mathrm{CB}}\right)$ и глутаминовая кислоты $(0,31-0,02$ г/кг СВ).

Результаты полукоксования сапропелей Омской области представлены в таблице 5. По соотношению величины полукокса к дегтю (ПК : Д) (в пересчете на органическую массу), характеризовалась химическая природа сапропелевых отложений. Если (ПК : Д) 2-3, то образование происходило за счет

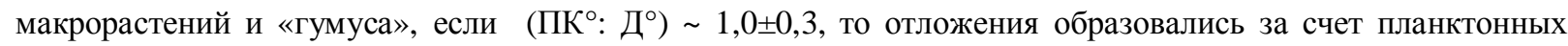
и бентоносных организмов.

Показано, что для сапропелей различных типов и степени разложения выходы первичной смолы при полукоксовании в стандартных условиях колеблется в пределах 14,5-65,0\%, а выходы полукокса $~ 3,8-$ $47,1 \%$ на органическое вещество.

Для значительной части исследуемых сапропелей Омской области показатель (ПК /Д) в пределах $1 \pm 0,3$, что свидетельствует о том что сапропели образовались преимущественно за счет планктонных и бентоносных организмов с меньшей примесью гумусового материала. Наиболее высокими показателями смолы и пониженными показателями полукокса на органическое вещество отличаются малозольные сапропели месторождений оз. Молоковское, Большой Артев и высокозольный сапропель оз. Чистое. Для высокозольного сапропеля оз. Чистое характерен повышенный выход газообразных продуктов, что, вероятно, объясняется частичным крекингом первичной смолы при полукоксовании под каталитическим воздействием золы.

Пониженными выходами смолы и повышенными выходами полукокса на органическую массу характеризуются образцы сапропелей оз. Тобол-Кушлы и Лепешкин Рям, очевидно, представляющие отложения гумусового характера.

Таблица 5. Выходы продуктов полукоксования сапропелей Омской области

\begin{tabular}{l|c|c|c|c|c|}
\hline \multirow{2}{*}{ Месторождение } & \multicolumn{4}{|c|}{ Выход продуктов полукоксования, \% масс. } & \multirow{2}{*}{ ПК /Д० } \\
\cline { 2 - 5 } & смола & \multicolumn{2}{|c|}{ на ОВ } & газ+потери & 2,11 \\
\cline { 2 - 5 } Тобол-Кушлы & на СВ & смола & полукокс & 30,6 & 0,63 \\
Кривое & 1,9 & 22,3 & 47,1 & 20,0 & 1,24 \\
Чебак & 6,4 & 49,2 & 30,8 & 57,9 & 0,26 \\
Чистое & 2,5 & 18,8 & 23,3 & 71,5 & 0,86 \\
Калмакульское & 3,1 & 22,6 & 5,9 & 26,0 & 0,64 \\
Горькое & 14,2 & 39,8 & 34,2 & 28,3 & 1,05 \\
Интенис & 15,8 & 43,8 & 27,9 & 25,1 & 1,27 \\
Пучай & 19,2 & 36,5 & 38,4 & 23,0 & 0,93 \\
Темное & 18,5 & 34,0 & 43,0 & 14,7 & 0,49 \\
Атаманское & 25,2 & 44,1 & 41,2 & 21,5 & 0,76 \\
Пахарево & 42,0 & 62,6 & 30,6 & 40,2 & 0,89 \\
Жилой Рям & 31,2 & 44,6 & 33,9 & 8,1 & 0,54 \\
Кайлы & 22,5 & 31,7 & 28,1 & 34,3 & 1,00 \\
Молодавское & 43,6 & 59,7 & 32,2 & 31,2 & 0,06 \\
Большой Артеев & 24,0 & 32,9 & 32,8 & 17,6 & 0,63 \\
Мезенино & 50,0 & 65,0 & 3,8 & 27,31 & 0,29 \\
Молоковское & 38,9 & 50,6 & 31,8 & 53,2 & 2,23 \\
Лепешкин Рям & 44,3 & 56,3 & 16,4 & 32,3 & \\
\hline
\end{tabular}

\section{Вblводbl}

В результате проведенных исследований показано, что сапропели Омской области различаются по составу и свойствам. Полученные сведения позволяют целенаправленно рекомендовать использовать тот или иной сапропель для конкретных технических приложений, при этом основным критерием, отвечающим за целесообразность переработки, является содержание органического вещества в объекте не менее $60 \%$. 


\section{Список литературы}

1. Штин С.М. Озерные сапропели и их комплексное освоение. М., 2005. 373 с.

2. Евдокимова Г.А., Успенская О.Н, Кухарчик В.В. Биологический и химический состав органического вещества малозольных сапропелей БССР // Химия твердого топлива. 1986. №2. С. 14-21.

3. Курзо Б.В., Богданов. Генезис и ресурсы сапропелей Белоруссии. Минск, 1989. 297 с.

4. Поздняк В.С., Раковский В.С. О химическом составе некоторых сапропелей Белорусской ССР // Труды института торфа. 1954. Т. 3. С. 109-119.

5. Бракш Н.А. Сапропелевые отложения и пути их использования. Рига, 1971. 187 с.

6. Добрецов В.Б. Сапропели России: освоение, использование, экология. М., 2005. 200 с.

7. Шмаков П.Ф., Третьяков А.Г., Левицкий В.А. Сапропелевые ресурсы озер омской области и их рациональное использование // Кормовые ресурсы Западной Сибири и их рациональное использование. Омск, 2005. C. 51-70.

8. Адеева Л.Н., Коваленко Т.А., Кривонос О.И., Плаксин Г.В., Струнина Н.Н. Определение химического состава сапропеля // Известия высших учебных заведений. Химия и химическая технология. 2009. Т. 52, вып. 3. C. $121-123$.

9. Шмаков П.Ф., Плаксин Г.В., Левицкий В.А. Химический состав и некоторые свойства сапропелей озер Омской области // Кормовые ресурсы Западной Сибири и их рациональное использование. Омск, 2005. С. 71-87.

10. Кривонос О.И., Плаксин Г.В. Использование до- и сверхкритического диоксида углерода для извлечения отдельных групп биологически активных веществ из сапропелей // Сверхкритические флюиды: теория и практика. 2010. Т. 5, № 3. С. 4-14.

Поступило в редакциию 10 октября 2013 г.

После переработки 13 января 20142. 
REGION

Krivonos O.I. ${ }^{1 *}$, Plaksin G.V. ${ }^{1,2}$, Nosenko V.N. ${ }^{2}$ ABOUT THE CHEMICAL COMPOSITION OF SAPROPELS OMSK

${ }^{1}$ Institute of Hydrocarbons Processing SB RAS, Neftezavodskaya str., 54, Omsk 644040 (Russia)

${ }^{2}$ Omsk F. M. Dostoevsky State University, Mira str., 55a, Omsk 644077 (Russia)

Studied chemical composition and physico-chemical properties of sapropel deposits of Omsk region. The regularities of linking the composition and properties of sapropel, and influence of temperature treatment of the output products.

Keywords: sapropel, chemical composition, biogenic trace elements, amino acids, semi-coking sapropels.

\section{References}

1. Shtin S.M. Ozernye sapropeli i ikh kompleksnoe osvoenie. [Lake sapropel and their integrated development]. Moscow, 2005, 373 p. (in Russ.).

2. Evdokimova G.A., Uspenskaia O.N, Kukharchik V.V. Khimiia tverdogo topliva, 1986, no. 2, pp. 14-21. (in Russ.).

3. Kurzo B.V., Bogdanov. Genezis i resursy sapropelei Belorussii. [Genesis and sapropel resources of Belarus]. Minsk, 1989, 297 p. (in Russ.).

4. Pozdniak V.S., Rakovskii V.S. Trudy instituta torfa, 1954, vol. 3, pp. 109-119. (in Russ.).

5. Braksh N.A. Sapropelevye otlozheniia i puti ikh ispol'zovaniia. [Sapropelic sediments and ways to use them]. Riga, 1971, 187 p. (in Russ.).

6. Dobretsov V.B. Sapropeli Rossii: osvoenie, ispol'zovanie, ekologiia. [Sapropels Russia: the development, utilization, ecology]. Moscow, 2005, 200 p. (in Russ.).

7. Shmakov P.F., Tret'iakov A.G., Levitskii V.A. Kormovye resursy Zapadnoi Sibiri i ikh ratsional'noe ispol'zovanie. [Food resources in Western Siberia and their rational use]. Omsk, 2005, pp. 51-70. (in Russ.).

8. Adeeva L.N., Kovalenko T.A., Krivonos O.I., Plaksin G.V., Strunina N.N. Izvestiia vysshikh uchebnykh zavedenii. Khimiia i khimicheskaia tekhnologiia, 2009, vol. 52, no. 3, pp. 121-123. (in Russ.).

9. Shmakov P.F., Plaksin G.V., Levitskii V.A. Kormovye resursy Zapadnoi Sibiri i ikh ratsional'noe ispol'zovanie. [Food resources in Western Siberia and their rational use]. Omsk, 2005, pp. 71-87. (in Russ.).

10. Krivonos O.I., Plaksin G.V. Sverkhkriticheskie Fliuidy: Teoriia i Praktika, 2010, vol. 5, no. 3, pp. 4-14. (in Russ.).

Received October 10, 2013

Revised January 13, 2014

\footnotetext{
* Corresponding author.
} 